\title{
Do medical cannabis growers attempt to produce cannabis with different cannabinoid concentrations than recreational growers?
}

Sharon R. Sznitman, Monica J. Barratt, Tom Decorte, Pekka Hakkarainen, Simon Lenton, Gary Potter, Bernd Werse and Chris Wilkins

\begin{abstract}
Purpose - It is conceivable that cannabis cultivators who grow for medical purposes aim to improve the therapeutic index of their cannabis by attempting to produce particular concentrations of CBD and/or THC. The purpose of this paper is to examine whether small-scale medical cannabis growers differ from those growing for recreational reasons in terms of self-assessed concentrations of THC and CBD in the cannabis they grow.

Design/methodology/approach - Data collection was conducted online from a convenience sample of 268 cannabis growers visiting a popular Israeli cannabis internet forum. $\chi^{2}$ and Kruskal-Wallis $\mathrm{H}$ were used to test bivariate associations between medical and recreational cannabis cultivators in terms of self-assessed cannabinoid concentrations.

Findings - In total, 40 percent of cannabis growers reported that they grow for medical purposes. Medical cannabis growers were more likely to report that they thought they knew the cannabinoid concentrations of the cannabis they grew and they reported higher self-assessed concentrations of THC, but not CBD.

Originality/value - Compared to recreational growers, medical cannabis growers are more likely to strive to be informed in terms of the content of their cannabis. Medical growers may also be attempting to grow more potent THC but not CBD cannabis.
\end{abstract}

Keywords Israel, Cannabis cultivation, Medical cannabis, CBD, Potency, THC

Paper type Research paper

\section{Introduction}

Cannabis is the most widely used controlled drug in the world. While most commonly used for recreational purposes (e.g. to get high, socialise), cannabis is increasingly being recognized and used as a remedy for various medical symptoms and conditions (The National Academies of Sciences, Engineering, and Medicine, 2017). Cannabis contains numerous cannabinoids, but $\Delta$ 9-tetrahydrocannabinol ( $T H C$ ) and cannabidiol (CBD) are typically the most concentrated components (Russo, 2011). THC is usually the most prevalent psychoactive constituent, producing the "high" associated with cannabis use. THC can also induce anxiety, psychotic-like experiences and cognitive impairment (Colizzi and Bhattacharyya, 2017). At the same time, research shows that $\mathrm{THC}$ possesses immunosuppressive and neuroprotective properties (Jamontt et al., 2010). Furthermore, research suggests that CBD has neuroprotective, anti-inflammatory and anti-oxidative properties (Campbell and Gowran, 2007; Cheng et al., 2014) and that it may attenuate the psychotic-like effects of THC (Russo, 2011).

Small-scale (non-commercial) domestic cannabis cultivation has grown rapidly in Europe and North America over recent years (Chadillon-Farinacci et al., 2015; Potter et al., 2015; Davenport and Caulkins, 2016). Yet, small-scale growing is likely to supply only a modest share
(Information about the authors can be found at the end of this article.)

(C) Sharon R. Sznitman, Monica J. Barratt, Tom Decorte, Pekka Hakkarainen, Simon Lenton, Gary Potter, Bernd Werse and Chris Wilkins. Published by Emerald Publishing Limited. This article is published under the Creative Commons Attribution (CC BY 4.0) licence. Anyone may reproduce, distribute, translate and create derivative works of this article (for both commercial \& non-commercial purposes), subject to full attribution to the original publication and authors. The full terms of this licence may be seen at: http:// creativecommons.org/licences/by/ 4.0/legalcode

Received 3 June 2019 Revised 7 August 2019 Accepted 3 September 2019

The National Drug and Alcohol Research Centre and the Nationa Drug Research Institute are supported by funding from the Australian Government under the Drug and Alcohol Program. The authors would like to thank Oren Lebovitch, the /sraeli Cannabis Magazine moderator, for hosting the survey and helping with recruitment. The authors would also like to thank the respondents who shared their experiences through taking part in the survey. 
of the overall cannabis market, especially in jurisdictions that have legalised cannabis which, in turn, is associated with increases in large-scale cannabis cultivation and "professionalisation" of the cannabis market (Davenport and Caulkins, 2016). Furthermore, research has found that people who report that they grow cannabis to provide themselves or others with cannabis for medical purposes (henceforth "medical cannabis cultivators") represent a substantial proportion of small-scale cannabis growers (Hakkarainen et al., 2015, 2017).

It is possible that "medical cannabis cultivators" differ from "recreational cannabis cultivators" in terms of the self-assessed THC and CBD concentrations in the cannabis they grow because of a desire to achieve a selective breed of cannabis that is thought to improve the therapeutic index. Because $\mathrm{THC}$ is the main psychoactive ingredient and because medical users may not seek the psychoactive effects of cannabis, medical cultivators may attempt to achieve lower levels of THC than recreational growers. Indeed, there is some evidence that medical cannabis patients prefer lower THC cannabis because it treats their symptoms without the accompanying psychoactive highs (Harris et al., 2000). Nevertheless, THC is known to have therapeutic effects and thus there is also reason to expect that medical growers may not attempt to produce lower THC concentrated cannabis than recreational growers. Since CBD is known to have therapeutic effects, but no psychoactive effects, medical cannabis cultivators may be more likely than recreational cannabis cultivators to attempt growing high CBD cannabis. It is also possible that the differences between growers lie in the CBD:THC ratio that due to the potential therapeutic benefits of both THC and CBD medical cannabis growers may be more likely to attempt a relatively balanced CBD:THC ratio.

The aim of this study is to expand the knowledge on medical cannabis cultivators by examining whether small-scale medical cannabis growers differ from those growing for recreational reasons in terms of self-assessed concentrations of THC and CBD in the cannabis they grow. The sample consists of small-scale cannabis growers in Israel. Israel is an interesting case study for the current project as it is the home of an established medical cannabis programme. Indeed, the Israeli Ministry of Health has been running a cannabis program since the 1990s and there are (as of 2017) approximately 28,000 licensed medical cannabis patients in Israel (Zarhin et al., 2018; Tandowski et al., 2019). There are eight private growers who legally supply these patients with medical cannabis. Israeli cannabis policies do not allow for home growing for medical or recreational purposes. Nevertheless, unlicensed medical cannabis use has been reported (Sznitman, 2017; Tandowski et al., 2019) and the current study focuses on a sample of cannabis cultivators who grow cannabis illegally.

\section{Methods}

Data for this study stem from the Israeli version of the International Cannabis Cultivation Questionnaire developed by the Global Cannabis Cultivation Research Consortium (GCCRC) to measure patterns of small-scale cannabis cultivation (Decorte et al., 2012). The methods and data of the GCCRC study have been described in depth elsewhere (Barratt et al., 2015). The current study is based on Israeli cannabis growers who reported cultivating within the last five years. Respondents were recruited through the Israeli Cannabis Magazine, a popular cannabis internet forum in Israel. A link to the online questionnaire was placed on the website and the forum moderator encouraged users to participate through social media. After informed consent was provided and inclusion criteria fulfilled (age > 17), respondents completed the anonymous survey. The study was approved by the Institutional Review Board of the Faculty of Social Welfare and Health Sciences at the University of Haifa.

\section{Variables}

Medical vs recreational growers. Medical vs recreational growers was measured by asking the respondents whether or not they grow in order to "provide others with cannabis for medical reasons" or "provide myself with cannabis for medical reasons." In total, 13 respondents reported growing to provide others with cannabis for medical reasons, 73 reported growing to provide themselves with cannabis for medical reasons and 13 other respondents reported in the affirmative to both questions. Sub-group analyses were not feasible due to insufficient cases in each category. Therefore, affirmative responses to any of these questions were coded as medical cannabis growers $(=1)$, otherwise respondents were coded as recreational growers $(=0)$. 
Cannabis concentrations. Respondents were coded in terms of whether they reported that they knew the concentrations of the cannabis they grow $(0=$ no, $1=$ yes). Those who answered in the affirmative were subsequently asked how they know the concentrations (by relying on source of seeds/cuttings; relying on feeling/experience; by measuring with a kit/laboratory) and to report, to the best of their knowledge, the average THC and CBD concentration in the cannabis they grow. We also calculated the THC:CBD ratio.

Sociodemographic variables. Sex $(0=$ female, $1=$ male), age (18-74), whether respondents had a university degree $(0=$ no, $1=$ yes $)$ and worked full time $(0=$ no, $1=$ yes $)$ were recorded.

\section{Statistical models}

Bivariate associations between medical and recreational cannabis cultivators and demographic background and cannabis concentrations were assessed using $\chi^{2}$ tests for categorical variables and Kruskal-Wallis $\mathrm{H}$ test (due to non-normal distributed data) for continuous variables. Statistical analyses were conducted with SPSS Inc. (2010).

\section{Results}

Almost all respondents were male (95 percent), the mean age was 28 years $(S D=8.58), 32$ percent of the sample had a university degree and 47 percent reported working full time (Table I). Overall 40 percent of cannabis growers reported that they grow for medical purposes. There was no significant difference between medical and recreational cannabis growers in terms of gender or average age $(p>0.05$ ). However, medical cannabis growers were less likely to have a university degree (25 vs 37 percent, $p=0.038$ ) and less likely to be working full time (34 vs 54 percent, $p=0.001$ ).

Medical cannabis growers were more likely to report that they thought that they knew the concentrations of the cannabis they grew compared to recreational cannabis growers (72 vs 57 percent, $p=0.006$ ). When conducting further analyses on the sub-sample that reported knowledge of cannabis concentrations ( $n=167$, Table II), results showed no differences in terms of methods used to test the concentrations. The most commonly reported source of knowledge was relying on source seeds/cuttings (75 percent) while very few (4 percent) reported relying on a kit/laboratory.

A large range of estimated cannabinoid concentrations was reported (THC: 3-42 percent; CBD: 0-44 percent). While there was no difference between medical and recreational growers in terms of assessed CBD concentration and THC:CBD ratio $(p>0.05)$, medical cannabis growers reported higher $\mathrm{THC}$ concentrations compared to recreational cannabis growers (mean $=20$ vs 17 percent, $p=0.026$ ).

$\mathrm{THC}$ and $\mathrm{CBD}$ concentrations as high as those reported by some of the respondents seem highly unlikely. For instance, in a recent report from the Netherlands, it was found that the highest THC cannabis content products on the market were 27 percent (Rigter and Niesink, 2017), whereas a few respondents in the current sample reported up to 42 percent THC. To test whether there were group differences once very extreme estimates were excluded, we tested mean differences again, this time excluding respondents reporting $\mathrm{THC}>27$ percent. Once these outliers were

\section{Table I Sample characteristics and bivariate associations between medical and recreational growers}

$$
\begin{array}{cccc} 
& \text { Recreational cannabis growers } & \text { Medical cannabis growers } & \\
\text { Total }(n=268) & (n=169,63.1 \%) & (n=99,39.6 \%) & \text { Statistical test }
\end{array}
$$

\section{Sociodemographic background}

Male, $n(\%)$

Age, mean (SD)

University degree, $n(\%)$

Work full time, $n(\%)$

Cannabis growing

Know potency, $n(\%)$
255 (95.1)

$28.02(8.58)$

86 (32.3)

125 (46.6)

$167(62.5)$
164 (97.0)

$27.91(7.98)$

$61(36.5)$

91 (53.8)

$96(56.8)$
91 (91.9)

28.21 (9.55)

25 (25.3)

34 (34.3)

$71(72.4)$ $\chi^{2}(1)=3.549, p=0.058$
$\chi^{2}(1)=0.324, p=0.569$
$\chi^{2}(1)=3.611, p=0.038$
$\chi^{2}(1)=9.541, p=0.001$

$\chi^{2}(1)=6.953, p=0.006$

VOL. 19 NO. 42019 DRUGS AND ALCOHOL TODAY $\mid$ PAGE 253 
Table II Bivariate associations in sub-sample $(n=167,62.5$ percent) that reported knowledge of potency

\begin{tabular}{|c|c|c|c|c|}
\hline & Total $(n=167)$ & $\begin{array}{l}\text { Recreational cannabis } \\
\text { growers }(n=96,57.5 \%)\end{array}$ & $\begin{array}{c}\text { Medical cannabis } \\
\text { growers }(n=71,42.4 \%)\end{array}$ & Statistical test \\
\hline Know by relying on source seeds/cuttings, $n(\%)$ & $124(75)$ & $73(77.7)$ & $51(71.8)$ & $\chi^{2}(1)=2.502, p=0.2 \varepsilon$ \\
\hline Know by relying on feeling/experience, $n(\%)$ & $34(20.6)$ & $19(20.2)$ & $15(21.1)$ & \\
\hline Know by measuring with a kit/laboratory, $n(\%)$ & $7(4.2)$ & $2(2.1)$ & $5(7.0)$ & \\
\hline$\%$ THC, mean (SD) & $18.31(6.19)$ & $17.30(5.02)$ & $19.63(7.28)$ & $\chi^{2}(1)=4.986, p=0.026$ \\
\hline$\%$ CBD, mean (SD) & $5.08(6.43)$ & $5.38(6.38)$ & $4.74(6.51)$ & $\chi^{2}(1)=0.101, p=0.751$ \\
\hline THC:CBD & $8.79(7.17)$ & $9.64(7.32)$ & $8.00(6.99)$ & $\chi^{2}(1)=0.483, p=0.487$ \\
\hline
\end{tabular}

Notes: THC, delta-9-tetrahydrocannabinol; CBD, cannabidiol

excluded there was no mean difference in assessed THC levels between recreational an medical cannabis growers; also, the exclusion did not change the insignificant mean difference found for the full sample for $\mathrm{CBD}$ and THC:CBD ratio.

\section{Discussion}

The current study shows that in this sample of Israeli cannabis cultivators, there is a relatively larg proportion of cultivators who grow for medical reasons. The results are consistent with those from separate Israeli sample of cannabis users, which found that 38 percent use cannabis for medice reasons (Sznitman, 2017), and an international study of small-scale cannabis growers, whic showed that 45 percent grow for medical purposes (Hakkarainen et al., 2017). It is, howeve important to point out that the current study was conducted in a self-selected sample of visitors an online discussion forum which limits the ability to assess its representativeness of cannabi growers in Israel. This method was, however, chosen because it provides ease of access, broac reach, anonymity and reduced response bias on sensitive topics (Ramo et al., 2012).

Results reported here further show that medical cannabis growers were more likely to report tha they thought they knew the concentrations of the cannabis they grow. This suggests that medica growers may have more interest in knowing the concentrations, potentially because they aim t improve the therapeutic index of their cannabis. Medical cannabis growers also reported highe self-assessed THC concentrations but not higher CBD concentrations which run counter to th expectation that medical cannabis users try to avoid or minimise the psychoactive effects of cannab (Harris et al., 2000). Yet, unpublished data from Israel show that medical cannabis licensed chron pain patients in Israel tend to use high THC cannabis (Meiri, 2019). One of the questions that th raises is that respondents may define themselves as medical growers as a strategy to minimis stigma and legitimise their growing and using practices, whereas the boundary between medical an recreational use is actually quite blurred (Hakkarainen et al., 2017). More research on how and wh some growers define themselves as medical growers is needed to explore this further.

The extent to which the self-reported concentration levels are correct is not possib to determine with the current data. Indeed, there is a potential discrepancy betweer self-assessments and actual concentrations of the cannabis produced, especially since ven few cultivators reported that they base their concentration assessment on kit/laborator testing. Furthermore, studies based on legally produced cannabis show discrepancies between actual THC and CBD content and the THC and CBD content reported on cannabi packaging (Vandrey et al. , 2015; Bonn-Miller et al., 2017), indicating that even in legal market the ability or willingness to objectively and correctly test THC and CBD content is limited There is therefore reason to believe that there are discrepancies between the self-assessed THC and CBD levels reported by our respondents and objectively measured levels. Th current results suggest that medical cannabis growers may be particularly prone to ove estimate the THC levels of their cannabis. Indeed, in sensitivity analyses excluding extreme high self-assessed THC estimates results failed to replicate the full sample result that medice cannabis cultivators report higher mean THC. Future research with objectively lab testec cannabinoid concentrations is needed to better understand the validity of self-reporte cannabinoid concentrations among small-scale growers.

\begin{tabular}{l|l|l} 
PAGE 254 & DRUGS AND ALCOHOL TODAY & VOL. 19 NO. 42019
\end{tabular} 
As opposed to interpreting the results of the THC/CBD self-assessments as objective indicators of cannabis concentrations produced by respondents in this sample, the assessments may be interpreted as growers' general aspirations and expectations in terms of the concentrations of the cannabis they grow. In this regard it is somewhat surprising that medical growers did not report higher $\mathrm{CBD}$ levels than recreational growers, seeing that $\mathrm{CBD}$ has no psychoactive effects but is known for its therapeutic effects. The results may be seen as an indication that medical growers are unaware of the therapeutic effects of CBD. It could also be the case that while they think that CBD is therapeutically beneficial, small/moderate dosages are seen as preferable. Considering the lack of research in this area there may be a need to conduct qualitative research in order to better understand the associations found in the current study.

The results presented in this paper show that medical cannabis growers may be particularly likely to aspire to improve the quality of their cannabis which suggests that they may be interested in reliable information and advice on what concentrations are suited to what conditions, and on how to produce cannabis with the most beneficial concentrations or THC:CBD ratio. At present, there is not enough research to inform the development of such guidelines. More research is needed that can provide safety guidelines for the use of different cannabis concentrations, how to achieve these levels and how to test for it.

\section{References}

Barratt, M.J., Potter, G.R., Wouters, M., Wilkins, C., Werse, B., Perälä, J., Pedersen, M.M., Nguyen, H., Malm, A., Lenton, S., Korf, D., Klein, A., Heyde, J., Hakkarainen, P., Frank, V.A., Decorte, T., Bouchard, M. and Blok, T. (2015), "Lessons from conducting trans-national internet-mediated participatory research with hidden populations of cannabis cultivators", International Journal of Drug Policy, Vol. 26 No. 3, pp. 238-49.

Bonn-Miller, M.O., Loflin, M.J.E., Thomas, B.F., Marcu, J.P., Hyke, T. and Vandrey, R. (2017), "Labeling accuracy of cannabidiol extracts sold online labeling accuracy of cannabidiol extracts sold online letters", Journal of the American Medical Association, Vol. 318 No. 17, pp. 1708-09.

Campbell, V.A. and Gowran, A. (2007), "Alzheimer's disease; taking the edge off with cannabinoids?", British Journal of Pharmacology, Vol. 152 No. 5, pp. 655-62.

Chadillon-Farinacci, V., Apparicio, P. and Morselli, C. (2015), "Cannabis cultivation in Quebec: between space-time hotspots and coldspots", International Journal of Drug Policy, Vol. 26 No. 3, pp. 311-22.

Cheng, D., Spiro, A.S., Jenner, A.M., Garner, B. and Karl, T. (2014), "Long-term cannabidiol treatment prevents the development of social recognition memory deficits in Alzheimer's disease transgenic mice", Journal of Alzheimer's Disease, Vol. 42 No. 4, pp. 1383-96.

Colizzi, M. and Bhattacharyya, S. (2017), "Does cannabis composition matter? Differential effects of delta-9-tetrahydrocannabinol and cannabidiol on human cognition", Current Addiction Reports, Vol. 4 No. 2, pp. 62-74, doi: 10.1007/s40429-017-0142-2.

Davenport, S.S. and Caulkins, J.P. (2016), "Evolution of the United States Marijuana Market in the decade of liberalization before full legalization", Journal of Drug Issues, Vol. 46 No. 4, pp. 411-27.

Decorte, T., Barratt, M.J., Nguyen, H., Bouchard, M., Malm, A. and Lenton, S. (2012), "International Cannabis Cultivation Questionnaire (ICCQ) (Version 1.1)", Global Cannabis Cultivation Research Consortium, available at: www.worldwideweed.nl/ (accessed April 14, 2014).

Hakkarainen, P., Frank, V.A., Barratt, M.J., Dahl, H.V., Decorte, T., Karjalainen, K., Lenton, S., Potter, G. and Werse, B. (2015), "Growing medicine: small-scale cannabis cultivation for medical purposes in six different countries", International Journal of Drug Policy, Vol. 26 No. 3, pp. 250-6.

Hakkarainen, P., Decorte, T., Sznitman, S.R., Karjalainen, K., Barratt, M.J., Frank, V., Lenton, S., Potter, G., Werse, B. and Wilkins, C. (2017), "Examining the blurred boundaries between medical and recreational cannabis - results from an international study of small-scale cannabis cultivation", Drugs: Education, Prevention \& Policy, Vol. 26 No. 3, pp. 250-8.

Harris, D., Jones, R.T., Shank, R., Nath, R., Fernandez, E., Goldstein, K. and Mendelson, J. (2000), "Self-reported marijuana effects and characteristics of 100 San Francisco medical marijuana club members", Journal of Addictive Diseases, Vol. 19 No. 3, pp. 89-103. 
Jamontt, J.M., Molleman, A., Pertwee, R.G. and Parsons, M.E. (2010), "The effects of $\Delta$ (9)-tetrahydrocannabin and cannabidiol alone and in combination on damage, inflammation and in vitro motility disturbances in rat colitis" British Journal of Pharmacology, Vol. 160 No. 3, pp. 712-23.

Meiri, D. (2019), "Personal communication with Dr. David Meiri, director of the laboratory of cancer biolog and cannabinoid research at the Technion's faculty of biology", Haifa, May.

Potter, G.R., Barratt, M.J., Malm, A., Bouchard, M., Blok, T., Christensen, A.S., Decorte, T., Frank, V.A Hakkarainen, P., Klein, A., Lenton, S., Perälä, J., Werse, B. and Wouters, M. (2015), "Global patterns o domestic cannabis cultivation: sample characteristics and patterns of growing across eleven countries" International Journal of Drug Policy, Vol. 26 No. 3, pp. 226-37.

Ramo, D.E., Liu, H. and Prochaska, J.J. (2012), "Reliability and validity of young adults' anonymous online report of marijuana use and thoughts about use", Psychology of Addictive Behaviors, Vol. 26 No. 4, pp. 801-11.

Rigter, S. and Niesink, R. (2017), "THC-concentraties in wiet, nederwiet en hasj in Nederlandse coffeeshops" Trimbos-instituut, Utrecht.

Russo, E.B. (2011), “Taming THC: potential cannabis synergy and phytocannabinoid-terpenoid entourag effects", British Journal of Pharmacology, Vol. 163 No. 7, pp. 1344-64.

SPSS Inc. (2010), SPSS Base 19.0 for Windows User's Guide, SPSS, Chicago, IL.

Sznitman, S.R. (2017), "Do recreational cannabis users, unlicensed and licensed medical cannabi users form distinct groups?", International Journal of Drug Policy, Vol. 42, April, pp. 15-21, doi: 10.1016/א drugpo.2016.11.010.

Tandowski, A., Zolotov, Y. and Sznitman, S.R. (2019), "Do users of diverted medical cannabis differ from other cannabis users?", Journal of Studies on Alcohol and Drugs, Vol. 80 No. 1, pp. 42-5.

The National Academies of Sciences, Engineering, and Medicine (2017), The Health Effects of Cannabis and Cannabinoids: The Current State of Evidence and Recommendation for Research, National Academies Press, Washington, DC.

Vandrey, R., Raber, J.C., Raber, M.E., Douglass, B., Miller, C. and Bonn-Miller, M.O. (2015), “Cannabinoi dose and label accuracy in edible medical cannabis products", Journal of the American Medical Association Vol. 313 No. 24, pp. 2491-3.

Zarhin, D., Negev, M., Vulfsons, S. and Sznitman, S.R. (2018), "Rhetorical and regulatory boundary-work: th case of medical cannabis policy-making in Israel", Social Science \& Medicine, Vol. 217, November, pp. 1-9

\section{Author Affiliations}

Sharon R. Sznitman is based at the School of Public Health, University of Haifa, Haifa, Israel.

Monica J. Barratt is based at Social and Global Studies Centre, RMIT University, Melbourne, Australia and National Drug and Alcohol Research Centre, UNSW, Sydney, Australia.

Tom Decorte is based at Institute for Social Drug Research, Ghent University, Ghent, Belgium.

Pekka Hakkarainen is based at Alcohol and Drugs Unit, National Institute for Health and Welfare (THL), Helsinki, Finland.

Simon Lenton is based at National Drug Research Institute, Curtin University, Perth, Australia.

Gary Potter is based at Law School, Lancaster University, Lancaster, UK.

Bernd Werse is based at Centre for Drug Research, Goethe-Universität, Frankfurt, Germany.

Chris Wilkins is based at SHORE \& Whariki Research Centre, Massey University, Auckland, New Zealan

\section{Corresponding author}

Sharon R. Sznitman can be contacted at: sznitmans@gmail.com

For instructions on how to order reprints of this article, please visit our website: www.emeraldgrouppublishing.com/licensing/reprints.htm

Or contact us for further details: permissions@emeraldinsight.com

\begin{tabular}{l|l|l} 
PAGE 256 & DRUGS AND ALCOHOL TODAY & VOL. 19 NO. 42019
\end{tabular} 